Fourth International Conference on Sustainable Construction Materials and Technologies http://www.claisse.info/Proceedings.htm

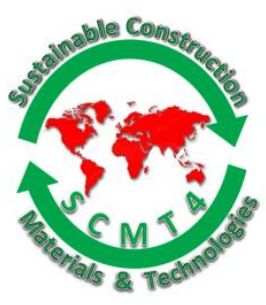

SCMT4

Las Vegas, USA, August 7-11, 2016

\title{
Utilization of Ceramic Waste Powder in Self-Compacting Concrete
}

\author{
Sama T. Ali ${ }^{1 a}$, Amr S. EL-Dieb*1b Sherif H. Aboubakr ${ }^{2 a}$ and Mahmoud M. Reda Taha ${ }^{2 b}$ \\ ${ }^{1}$ Civil and Environmental Engineering Department, United Arab Emirates Univ., UAE \\ ${ }^{1 a}$ Email: <200935093@uaeu.ac.ae>,1bEmail: 〈amr.eldieb@uaeu.ac.ae>. \\ ${ }^{2}$ Department of Civil Engineering, Univ. of New Mexico, USA \\ ${ }^{2 a}$ Email: <sherif@unm.edu>, ${ }^{2 b}$ Email: <mrtaha@unm.edu>.
}

\begin{abstract}
Self-compacting concrete (SCC) mixtures include high powder content (i.e. $450-600 \mathrm{~kg} / \mathrm{m}^{3}$ ) which is needed to maintain sufficient stability/cohesion of the mixture and hence improving segregation resistance. The use of high cement content to meet the need of high powder is not desirable as it will increase the cost and has other negative effects on concrete properties. The requirement for high powder content in SCC is usually met by using mineral admixtures such as slag, fly ash and/or less reactive filler materials such as limestone powder and granite powder.

Ceramic waste powder (CWP) produced during the polishing process of ceramic tiles are dumped in landfills and can cause soil, air and groundwater pollution making a serious environmental problem. CWP is characterized by its fine particles' size and chemical composition which is mainly $\mathrm{SiO}_{2}$ and $\mathrm{Al}_{2} \mathrm{O}_{3}$ (i.e. more than $80 \%$ ). This makes CWP a very good candidate to be used as filler in SCC. Therefore, the utilization of CWP would achieve sustainable SCC with strong environmental incentives.

In this study the utilization of CWP in making SCC is evaluated. The study involves two experimental phases. In the first phase; the main characteristics of the ceramic waste powder (i.e. chemical composition, specific surface area and scanning electron microscope) are examined. In the second phase; the effect of using CWP on fresh concrete properties and mechanical properties of SCC are investigated. It is found that CWP can be used to successfully produce SCC mixtures with improved fresh and hardened concrete properties.
\end{abstract}

\section{INTRODUCTION}

Sustainable waste management is an ongoing trend worldwide nowadays. This is accomplished through the utilization of recycled waste products in construction particularly concrete industry. This approach is considered an efficient way both economically and environmentally towards saving the exhausted landfills where huge amounts of industrial solid waste are being deposited annually. This waste management technique will also contribute towards reducing the carbon footprint on our ecological system produced from the great energy consumption used during cement manufacturing. It's estimated that the production 
of one ton of cement generates an equivalent amount of $\mathrm{CO}_{2}$ [Sadek et al. 2014]. The incorporation of industrial waste as alternative constituents in concrete industry will reduce the reliance on natural nonrenewable ingredients, and hence lower the quick depletion rate of raw minerals [Rahhal et al. 2014]. It will also help reducing the construction cost. Various industrial by-products have been widely used as less expensive cement substitutes and were proven to enhance the produced concrete properties both fresh and hardened [Uysal and Yilmaz 2011].

Self compacting concrete has been considered a great development in the construction field since it was first introduced in Japan in the late 20th century. This type of concrete inherits superior advantages over the traditional concrete. It is featured with high fluidity yet no segregation, and is placed under its own weight without the need for vibration. Large quantities of powder materials named generally as fillers or mineral admixtures are used to reduce the frequency of collision between particles and hence improve the flowability [Siddique and Kunal 2015]. Given the advantages SCC offers, many researchers have examined the role of different types of fillers both inert and reactive such as limestone powder, fly ash, and marble stone dust. For instance, [Pansesar and Aqel 2014] investigated the effect of replacing cement with limestone powder that resulted in higher compressive strength. Furthermore, a study conducted on marble powder [Alyamac and Ince, 2009] concluded that it had negligible effect on the flowability but can result in higher compressive strength compared to conventional concrete at a given $\mathrm{w} / \mathrm{c}$ ratio.

The ceramic products have been widely used in several applications in the building construction for a very long time. Unfortunately, the waste powder produced from the polishing process of the final ceramic products is generated in very large amounts and its disposal to landfills leads to great environmental problems. Therefore, the main aim of this study is to investigate the feasibility of utilizing ceramic waste powder (CWP) as filler material in self compacted concrete (SCC), and to examine its effect on both fresh and hardened properties.

\section{EXPERIMENTAL INVESTIGATION}

Materials. During the experimental work of this study, ordinary Portland cement Type I conforming to ASTM 150 was used. Natural coarse aggregates were obtained from Ras Al Khaima. The nominal maximum size, specific gravity, and absorption $\%$ of the used coarse aggregates were $10 \mathrm{~mm}, 2.65$ and $1.0 \%$ respectively. While for the fine aggregates, two types were used namely: dune sand and crushed sand aggregates, with fineness modulus of 1.00 and 3.90 respectively. The specific gravity of the used fine aggregates was 2.63 .

Ground granulated blast furnace slag (i.e. slag) was used as filler in some of the mixtures with a specific surface area $432 \mathrm{~m}^{2} / \mathrm{kg}$ and a specific gravity 2.93 .

Chemical analysis of CWP was conducted and showed that CWP is mainly composed of silica $\left(\mathrm{SiO}_{2}\right)$ forming about $69.4 \%$ of the material. Furthermore, alumina also represents another major compound of CWP making about $18.2 \%$. The total mix of silica and alumina oxides in CWP exceeds $80 \%$ of the total material weight. Other compounds included 3.19\% $\mathrm{Na}_{2} \mathrm{O}, 3.53 \% \mathrm{MgO}, 0.306 \% \mathrm{Cl}, 1.89 \% \mathrm{~K}_{2} \mathrm{O}, 1.24 \%$ $\mathrm{CaO}, 0.617 \mathrm{TiO}_{2}, 0.83 \% \mathrm{Fe}_{2} \mathrm{O}_{3}, 0.266 \% \mathrm{ZrO}_{2}$. Specific surface area (SSA) measurements using Blaine fineness method showed CWP to have SSA of $555 \mathrm{~m}^{2} / \mathrm{kg}$. The morphology of CWP was observed using scanning electron microscope (SEM) as shown in Figure 1.

For both groups, polycarboxylic ether based superplasticizer (Glenium® sky 504) and a high molecular weight synthetic co-polymer viscosity modifying admixture (VMA) (RheoMATRIX ${ }^{\circledR} 110$ ) were used to improve the rheological properties of the mixtures. The optimum admixture dosages were chosen based on trial mixtures. The amount varied from $1.28 \%$ to $1.7 \%$ for the superplasticizer and from $0.29 \%$ to $0.33 \%$ for the VMA by weight of the binder content. 

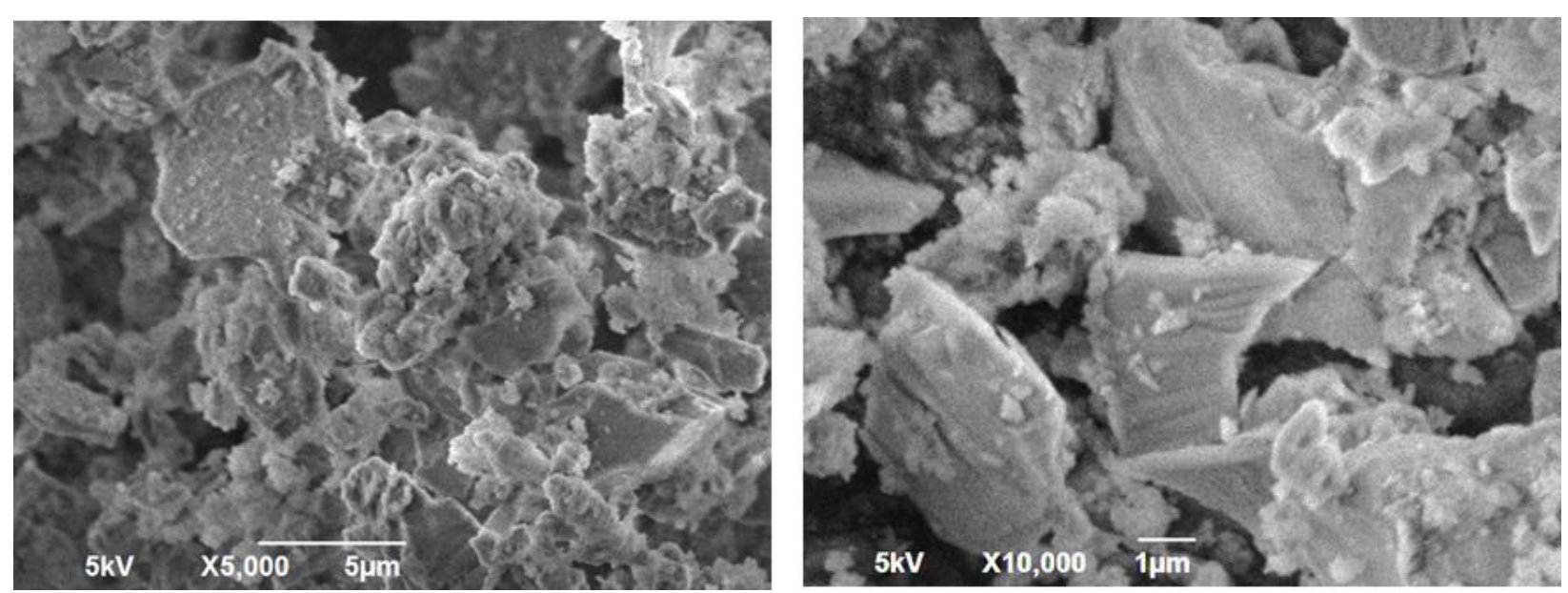

Figure 1. SEM of Used CWP.

Mix proportions. Tables 1 and 2 present the concrete mixture proportions. Two groups of mixtures were cast to investigate the addition of ceramic powder to the mixture and the replacement of cement by ceramic powder. In the first group the cement content in the control mixture (A-S-100) was $350 \mathrm{~kg} / \mathrm{m}^{3}$ based on the preliminary mix design, which is below the value recommended by EFNARC-2005 specifications (i.e. powder content $\geq 450 \mathrm{~kg} / \mathrm{m}^{3}$ ). To meet the specifications' requirements, slag was added as filler in the amount of $100 \mathrm{~kg} / \mathrm{m}^{3}$ to fulfil the minimum powder content and to act as control mixtures. In mixes (A-S200 and A-S-300) the amount of slag was gradually increased to 200 and $300 \mathrm{~kg} / \mathrm{m}^{3}$ respectively while maintaining the total powder content at $450 \mathrm{~kg} / \mathrm{m}^{3}$. Similarly, CWP was used in replacement of the slag (i.e. A-C-100, A-C-200 and A-C-300). For this group, the w/cm ratio used was (0.41).

For the second group of mixtures, the initial cement content in the control mixture (R-0) was above the recommended value by EFNARC-2005 specifications without the need of any additional filler. The cement was partially replaced by the CWP in 20, 40 and $60 \%$ which are equivalent to 100,200 and $300 \mathrm{~kg} / \mathrm{m}^{3}$ respectively (R-100, R-200, and R-300). For this group, the w/cm ratio used was (0.35).

The two groups were expected to yield compressive strength in the range of 60 to $80 \mathrm{MPa}$.

\section{MIXTURE PERFORMANCE EVALUATION}

Several tests were conducted to investigate the effect of CWP on both fresh and hardened properties of concrete. During the fresh stage, unconfined flowability of the produced SCC mixture was assessed by the slump flow test in accordance to ASTM C1611. The segregation resistance was evaluated through conducting the GTM segregation column test according to ASTM C1610. Correspondingly, strength was conducted at four different test ages $(7,28,56$, and 90 days) on three $100 \mathrm{~mm}$ cubes at each test age and the average strength was calculated. Regarding the durability characteristics of the mixtures, it was examined through conducting the rapid chloride permeability test (RCPT) as per ASTM C1202. The RCPT was conducted on concrete disc $(100 \mathrm{~mm}$ diameter x $50 \mathrm{~mm}$ thickness) cut from the middle third of concrete cylinders. RCPT was performed on 2 specimens at two ages (28 and 90 days). Finally, Brunauer-EmmettTeller (BET) $\mathrm{N}_{2}$ measurement of porosity was performed on hardened cement pastes incorporating $0 \%$, $20 \%$ and $40 \%$ CWP as replacement of cement representing concrete mixes R-0, R-100 and R-200. BET measurements aimed to determine the pore size distribution. The Barrett-Joyner-Halenda (BJH) analysis method was conducted to identify the change in cement paste porosity with incorporating CWP. 
Table 1. Mixture Proportions with Slag and CWP as Addition

\begin{tabular}{|l|c|c|c|c|c|c|}
\hline \multirow{2}{*}{ Mixture Ingredients } & \multicolumn{6}{|c|}{ Mixture Designation } \\
\cline { 2 - 7 } & A-S-100 & A-C-100 & A-S-200 & A-C-200 & A-S-300 & A-C-300 \\
\hline Cement $\left(\mathrm{kg} / \mathrm{m}^{3}\right)$ & 350 & 350 & 250 & 250 & 150 & 150 \\
\hline Slag $\left(\mathrm{kg} / \mathrm{m}^{3}\right)$ & 100 & 0 & 200 & 0 & 300 & 0 \\
\hline CWP $\left(\mathrm{kg} / \mathrm{m}^{3}\right)$ & 0 & 100 & 0 & 200 & 0 & 300 \\
\hline Water $(\mathrm{Liters})$ & 184 & 184 & 184 & 192 & 184 & 184 \\
\hline FA $^{1}$, Dune Sand $\left(\mathrm{kg} / \mathrm{m}^{3}\right)$ & 484 & 484 & 482 & 482 & 480.2 & 480.2 \\
\hline FA $^{1}$, Crushed Stone $\left(\mathrm{kg} / \mathrm{m}^{3}\right)$ & 484 & 484 & 482 & 482 & 480.2 & 480.2 \\
\hline CA $^{2} 10-\mathrm{mm}$ max. $\left(\mathrm{kg} / \mathrm{m}^{3}\right)$ & 792 & 792 & 771 & 771 & 785.7 & 785.7 \\
\hline Super Plasticizer $\left(\mathrm{kg} / \mathrm{m}^{3}\right)$ & 5.75 & 5.75 & 3 & 4.8 & 5.75 & $11.15^{*}$ \\
\hline VMA $\left(\mathrm{kg} / \mathrm{m}^{3}\right)$ & 1.25 & 1.25 & 1.25 & 1.25 & 1.25 & 1.25 \\
\hline W/Cm & 0.41 & 0.41 & 0.41 & 0.41 & 0.41 & 0.41 \\
\hline
\end{tabular}

*high dosage of admixtures was used in this mix due to high casting temperature $\left(40-45^{\circ} \mathrm{C}\right)$.

${ }^{1}$ Fine Aggregates

${ }^{2}$ Coarse Aggregates

Table 2. Mixture Proportions with CWP as Cement Replacement

\begin{tabular}{|l|c|c|c|c|}
\hline \multirow{2}{*}{\multicolumn{1}{|c|}{ Mixture Ingredients }} & \multicolumn{4}{|c|}{ Mixture Designation } \\
\cline { 2 - 5 } & $\mathrm{R}-0$ & $\mathrm{R}-100$ & $\mathrm{R}-200$ & $\mathrm{R}-300$ \\
\hline Cement $\left(\mathrm{kg} / \mathrm{m}^{3}\right)$ & 500 & 400 & 300 & 200 \\
\hline Slag $\left(\mathrm{kg} / \mathrm{m}^{3}\right)$ & 0 & 0 & 0 & 0 \\
\hline CWP $\left(\mathrm{kg} / \mathrm{m}^{3}\right)$ & 0 & 100 & 200 & 300 \\
\hline Water $(\mathrm{Liters})$ & 175 & 175 & 175 & 175 \\
\hline FA, Dune Sand $\left(\mathrm{kg} / \mathrm{m}^{3}\right)$ & 479 & 479 & 479 & 479 \\
\hline FA, Crushed Stone $\left(\mathrm{kg} / \mathrm{m}^{3}\right)$ & 392 & 392 & 392 & 392 \\
\hline CA, $10-\mathrm{mm}$ max. $\left(\mathrm{kg} / \mathrm{m}^{3}\right)$ & 871 & 871 & 871 & 871 \\
\hline Super Plasticizer $\left(\mathrm{kg} / \mathrm{m}^{3}\right)$ & 8.33 & 8.72 & 8.33 & 8.80 \\
\hline VMA $\left(\mathrm{kg} / \mathrm{m}^{3}\right)$ & 1.6 & 1.6 & 1.6 & 1.6 \\
\hline W/Cm & 0.35 & 0.35 & 0.35 & 0.35 \\
\hline
\end{tabular}

\section{RESULTS AND DISCUSSIONS}

\section{Fresh concrete tests}

Slump flow test. Figures 2 and 3 illustrate the effect of slag and CWP on the flowability of the SCC mixtures. From the figures, we can conclude that increasing the amounts of slag or CWP in the mixtures reduce the flowability yet keeping it within the range recommended by EFNARC-2005. This can be attributed to the the higher water demand due to the increase of SSA of the particles (from $380 \mathrm{~m}^{2} / \mathrm{kg}$ for cement to $555 \mathrm{~m}^{2} / \mathrm{kg}$ for CWP and $432 \mathrm{~m}^{2} / \mathrm{kg}$ for slag). Moreover, the irregular shape of the CWP particles that is assumed to reduce the ability of the mixture to expand, leading to reduced slump flow diameters. In the addition group, both the slag and CWP mixtures exhibited similar behaviour, that is as more filler is being added to the mixtures, lower slump flow values are obtained. 


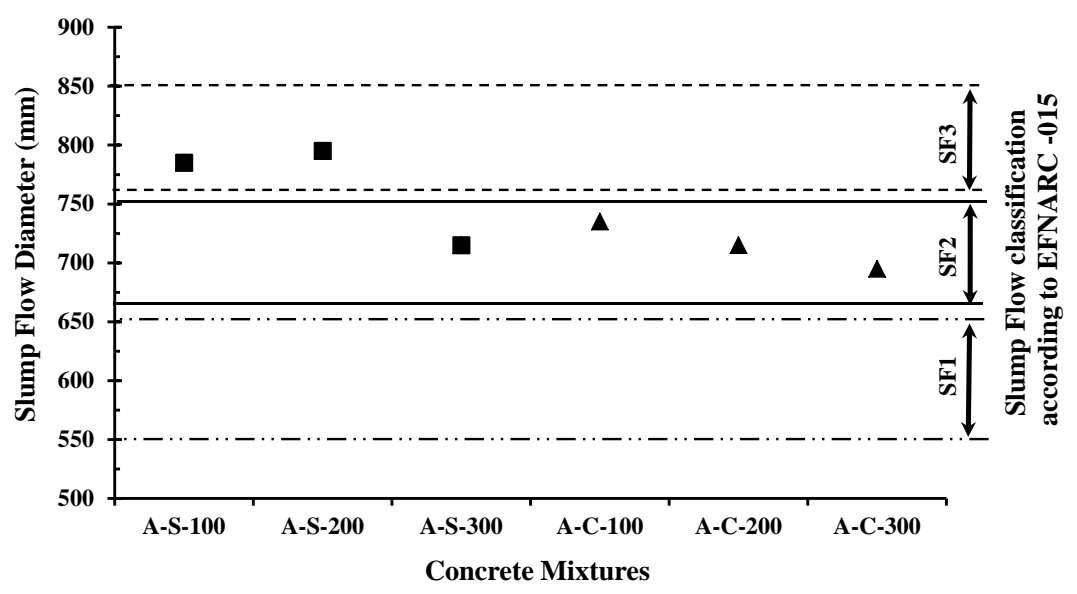

Figure 2. Slump Flow Results of Mixtures with Slag and CWP as Addition.

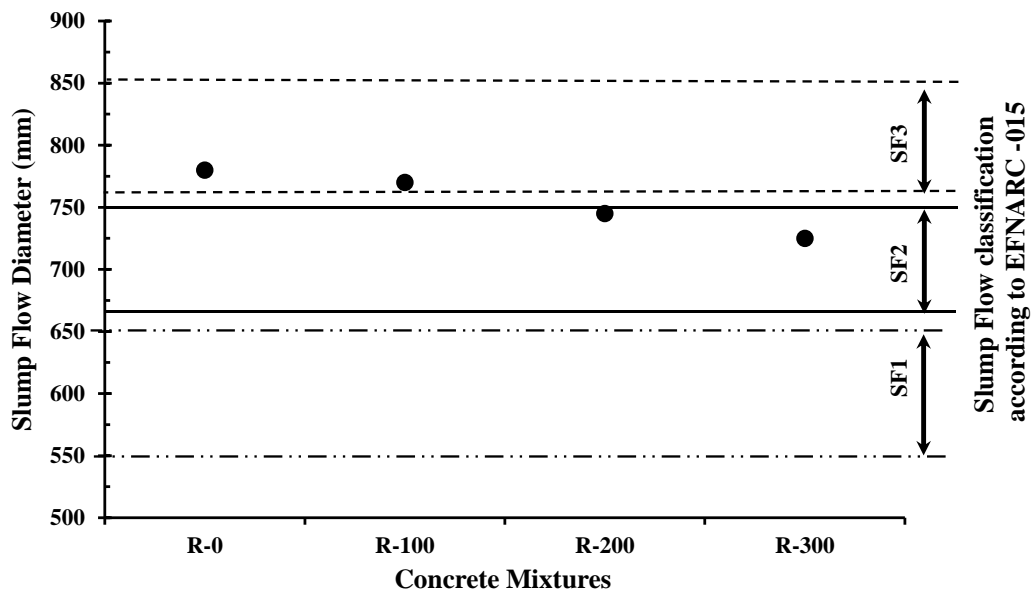

Figure 3. Slump Flow Results of Mixtures with CWP as Cement Replacement.

Segregation resistance. Segregation resistance is the ability of concrete to remain homogenous in composition in fresh state [Heirman et al. 2008, and Lachemi et al, 2007] related segregation resistance to viscosity, where they stated that higher viscosity can result in lower segregation. The trend in all the ten SCC mixtures casted shown in Figures 4 and 5 show that as the quantity of CWP added to the mixture is increased, the segregation resistance of the mixtures is enhanced. When the powder content is generally increased, the viscosity is increased and accordingly results in lower segregation [Liu. 2011].

\section{Hardened concrete tests}

Compressive strength. Figure 6 illustrates the differences in strength between the CWP and slag in the addition group. It's obvious that as the addition level increases, the strength values decrease in both groups. This can be attributed to the fact that the cement is being replaced, which is the cementing component responsible for strength development. The high strength obtained at 90 days for CWP can be explained by its physical properties, where the SSA $\left(555 \mathrm{~m}^{2} / \mathrm{kg}\right)$ is relatively very high allowing it to act as a micro-filler. In addition to this, its chemical composition and in particular its high content of $\mathrm{SiO}_{2}$ and $\mathrm{Al}_{2} \mathrm{O}_{3}$ contributed in the activity not only as a filler but partially as a binder due to potential pozzolanic characteristics. 


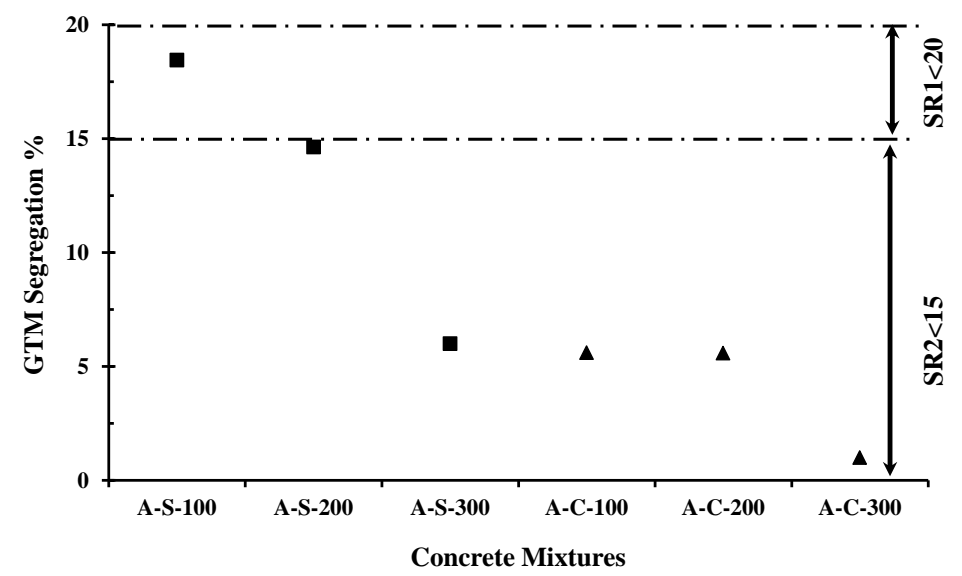

Figure 4. GTM Segregation Column Test Results of Mixtures with Slag and CWP as Addition

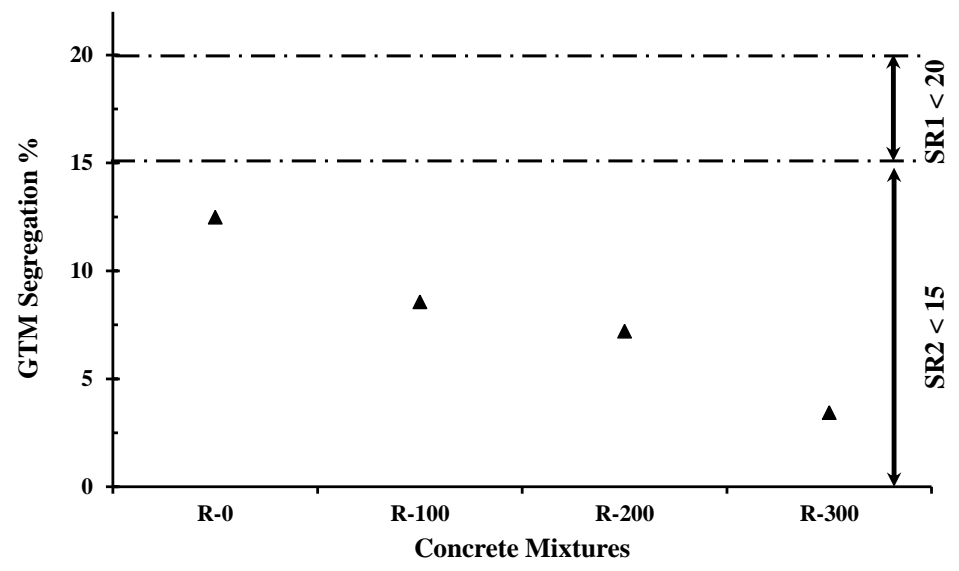

Figure 5. GTM Segregation Column Test Results of Mixtures with CWP as Cement Replacement

Figure 7 shows the strength development among the four replacement mixtures. At 7 days of concrete age, the highest compressive strength value achieved was in mix R-0 (66 MPa). This strength value is due to the high amount of hydration products produced due to the presence of high cement content. As this amount of cement decreases gradually, the early age strength decreases. After 90 days of age, the mixtures incorporating CWP start to acquire higher strength values compared to the control mixture (R-0). This trend is maintained up to the replacement level of $200 \mathrm{~kg}$, after which any additional replacement results in strength values lower than that of the control mix. Here the role of CWP might be better understood not just as filler but also as a binding material enhancing concrete strength. The best performance occurs at the 100 $\mathrm{kg}$ replacement due to CWP physical nature contributing through a dense packing effect improving the microstructure. The decrease in compressive strength in R-300 might be due to the fact that the amount of silica was too high and the amount of the produced calcium hydroxide $(\mathrm{CH})$ as a cement hydration product was most likely insufficient to react with all the available silica and as a result some amount of silica was left without chemical reaction. It can also be due to increased porosity as a result of higher CWP content. 


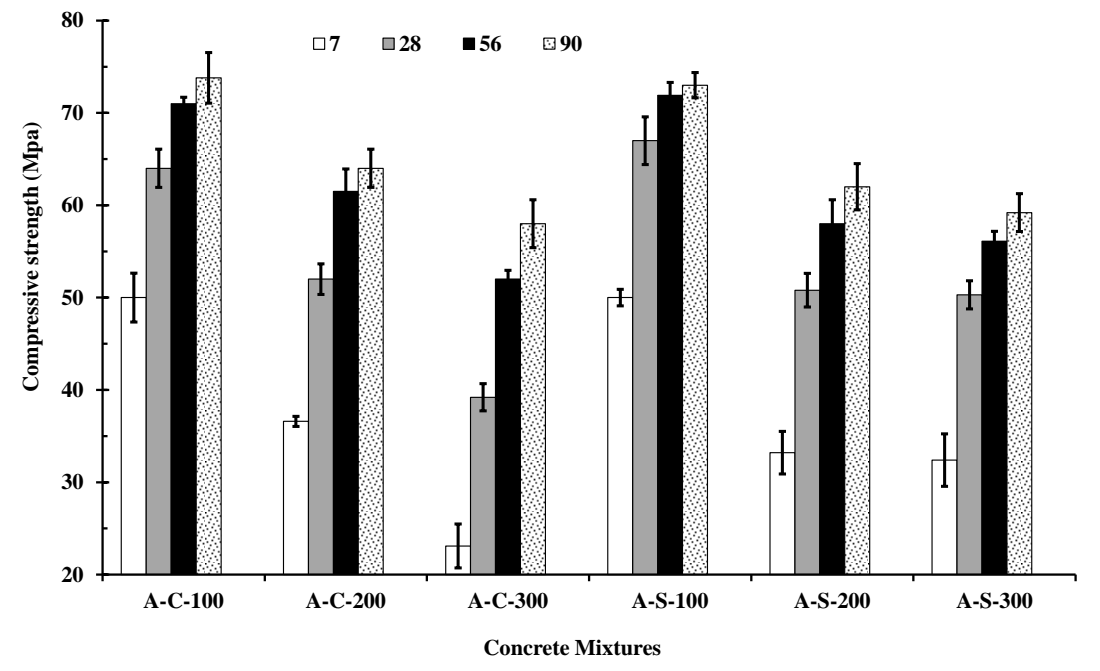

Figure 6. Compressive Strength for Mixtures with Slag and CWP as Addition

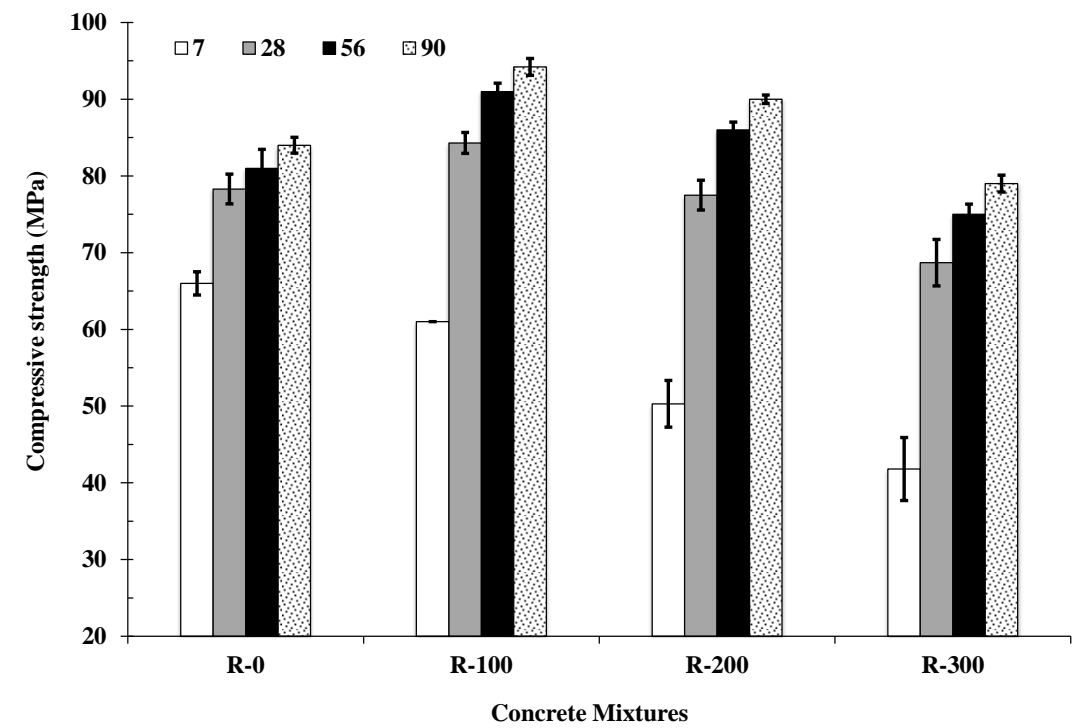

Figure 7. Compressive Strength for Mixtures with CWP as Cement Replacement

RCPT. The results of the chloride ion permeability measured in terms of the electrical charge passing through the concrete discs in coulombs are presented in Figures 8 (a) and (b). The permeability of chloride ions decreased as the amount of CWP increased in all mixtures. This trend is also similar within the individual mixtures as the age increases from 28 to 90 days. This can be due to the fact that CWP mixtures have lower porosity than those of slag and cement, which can be attributed to the finer particle size distribution for CWP that may have resulted in micro-filling effect and densifying the concrete microstructure.

From Figure 8(a), it is obvious that there is a significant difference in the charge passing in the addition group. An important fact to outline here is that the chloride permeability at 28 days in mixtures with only $100 \mathrm{~kg}$ addition of CWP achieved almost similar resistance compared to mixtures with addition level of $300 \mathrm{~kg}$ of slag. All mixtures with CWP exhibited "Very Low" chloride permeability as per ASTM C1202. The corresponding mixtures produced with slag as filler resulted in chloride permeability classes ranging from "Very Low" to "Low" as the age of the concrete increases. 

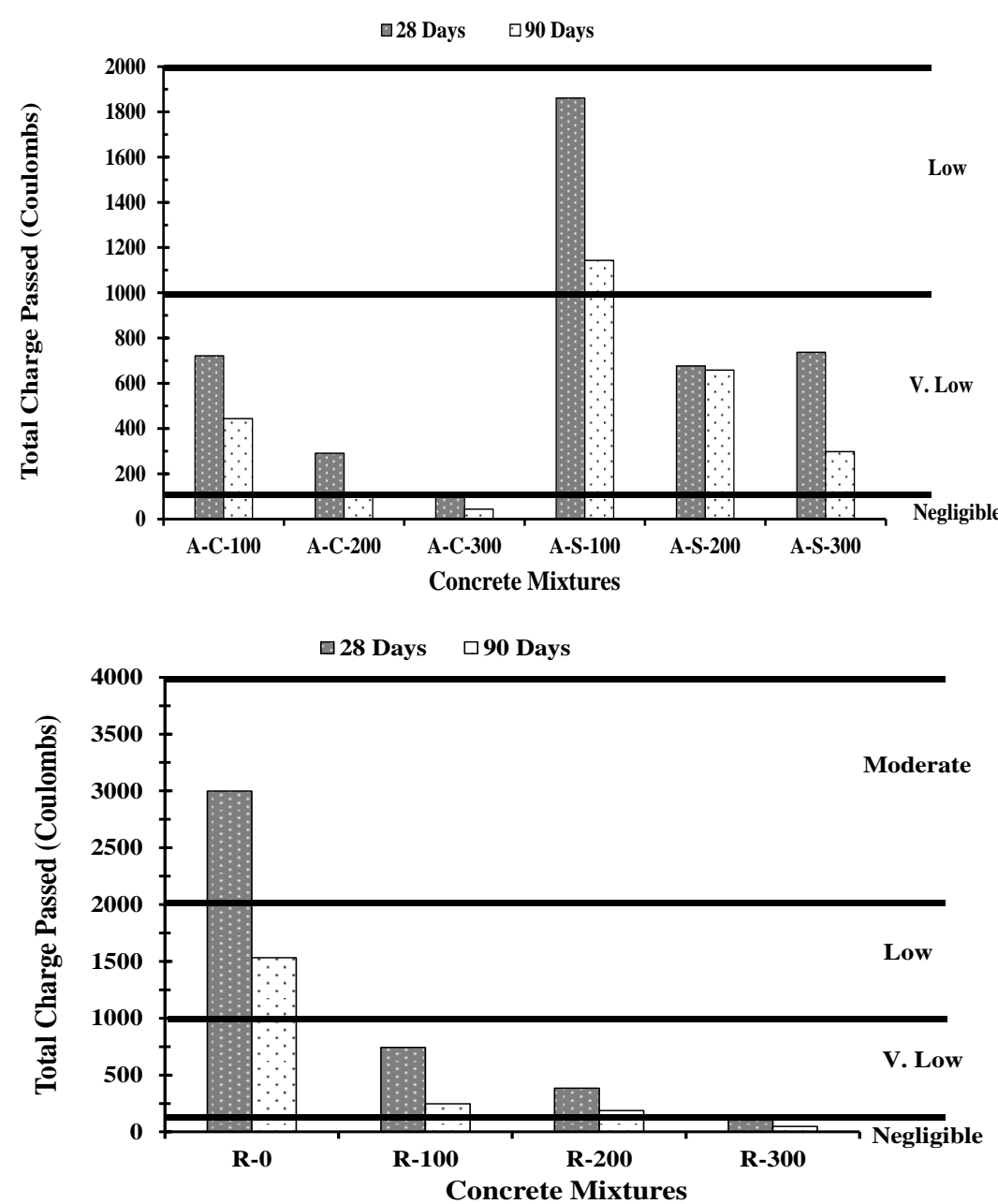

(a)

(b)

\section{Figure 8. RCPT Results of Concrete Mixtures (a) Incorporating Slag and CWP as Addition (b) Incorporating CWP as replacement of cement}

From Figure 8(b), there appears to be a considerable difference between the R- 0 with no CWP and the R300 with the highest CWP content. The incorporation of CWP had a substantial effect on enhancing the resistance to chloride ion permeability of the concrete mixtures. The permeability actually improved at an order of two classes: from "Low" to "Negligible" at 90 days according to ASTM C1202 classifications when the replacement level of CWP was increased from 0 to $300 \mathrm{~kg}$ respectively.

Figure 9 shows the BET isotherms of cement paste with 0,20 and $40 \%$ cement replacement by CWP. BJH cumulative adsorption and desorption pore volume is presented in Table 3 confirming. The isotherm figures in Figure 9 and Table 3 shows a drop of the isotherm and the pore volume when 20\% of the cement was replaced by CWP indicating an improved concrete microstructure with reduced porosity due to inclusion of CWP. However, incorporating $40 \%$ of CWP results in increasing of the pore volume. These observations might be explained by the ability of the limited amount of $20 \%$ CWP to reduce cement paste/concrete porosity through its filling effect and potential pozzolanic effect. As the CWP content increased to 40\%, its own porosity overcomes the improvement it made in cement paste and thus the total porosity increases. It seems that a limited amount of CWP (20-30\%) might be optimal for improving cement paste and therefore concrete microstructure. BET observations explain the good improvement of compressive strength at $20 \%$ CWP and the limited change at 40\% CWP compared with 20\% CWP shown in Figure 7. It is evident that a 
limited amount of CWP (20-30\% replacement of cement by weight) makes a good effect of concrete. Further research is warranted to understand CWP effect being a filler, a pozzolanic material or a mix of both.

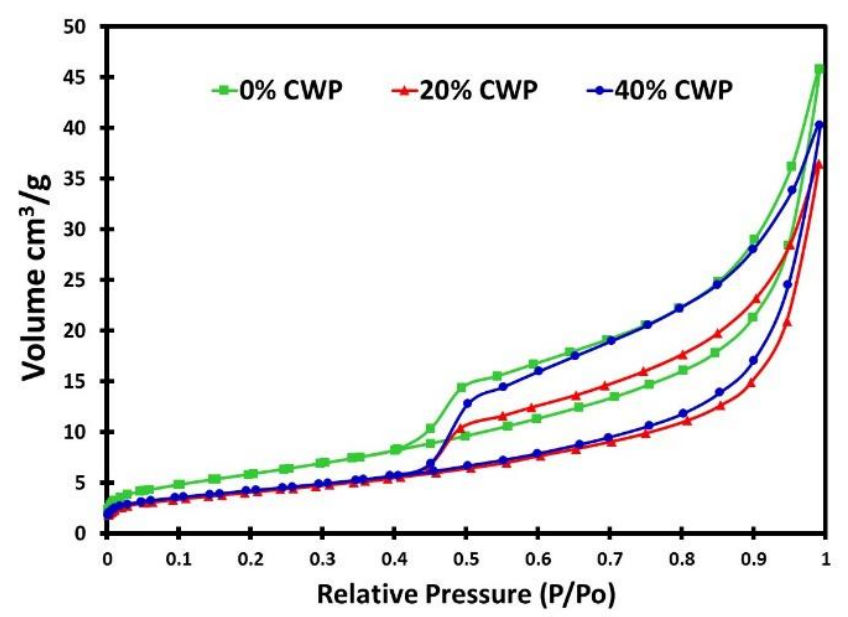

Figure 9. BET Isotherms of Portland Cement without and with CWP Replacement.

Table 3. BJH Cumulative Adsorption and Desorption Pore Volume with CWP as Replacement of Cement

\begin{tabular}{|c|c|c|c|}
\hline Pore Volume $\mathrm{cm}^{3} / \mathrm{g}$ & $0 \% \mathrm{CWP}$ & $20 \% \mathrm{CWP}$ & $40 \% \mathrm{CWP}$ \\
\hline Adsorption & 0.076 & 0.058 & 0.066 \\
\hline Desorption & 0.077 & 0.063 & 0.073 \\
\hline
\end{tabular}

\section{CONCLUSION}

The following general conclusions can be drawn from the study provided in the paper:

- CWP has potential for producing self-compacting concrete.

- All mixtures exhibited satisfactory fresh state properties according to the criteria established by the EFNARC-2005 specifications and ASTM standards.

- The incorporation of higher amounts of slag produces SCC mixtures with lower flowability and better segregation values.

- The combined effect of the high surface area and irregular particle shape of CWP reduced the slump flow and improved the segregation resistance of the mixtures.

- Concrete mixtures with CWP resulted in a much higher resistance to chloride ions than mixtures with slag and cement, and hence would exhibit very good protection against corrosion. This is due to the better packing efficiency provided by the fine particles of CWP in the produced SCC mixtures.

- Considerable strength development was obtained in the mixtures incorporating CWP as cement replacement up to $20 \%$ replacement level with strength higher than the control mixture (R-0).

- The concrete mixtures incorporating slag and CWP as addition interchangeably as fillers resulted in very close strength values at the corresponding replacement levels.

- BET measurements of cement paste incorporating CWP as replacement of cement proved the ability of limited amount of CPW (about 20-30\%) to reduce cement paste porosity. CPW contents higher than $30 \%$ replacement of cement, results in porosity structure similar to original cement paste. 
- It is apparent that limited replacement of cement by CWP (20-30\% by weight) enables good reduction in cement paste/concrete porosity and thus improves mechanical and durability characteristics of SCC.

- Further research is warranted to understand CWP role in concrete as a filler material, a pozzolanic material or both.

\section{ACKNOWLEDGEMENTS}

This work was financially supported by the UAEU-UPAR2 Research Grant \# 31N2018. Also, the donation of the ceramic waste powder for the study by PORCELLAN (ICAD II MUSSAFAH - ABU DHABI) and the cooperation of Eng. Mostafa Gad Alla and Mr. Dilip Kumar Borah are highly appreciated.

\section{REFERENCES}

Alyamac, K.E. and Ince, R. (2009). "A Preliminary Concrete Mix Design for Self-Compacting Concrete with Marble Powders." Construction and Building Materials, 23(3), 1201-1210.

EFNARC (European Federation of national trade associations representing producers and applicators of specialist building products). (2005). The European guidelines for self-compacting concrete: Specification, production and Hampshire, U.K., (http://www.efnarc.org/pdf/SCCGuidelinesMay2005.pdf), 68p.

Heirman, G., Vandewalle, L., Van Gemert, D., Boel, V., Audenaert, K., De Schutter, G. and Vantomme, J. (2008). "Time-Dependent Deformations of Limestone Powder Type Self-Compacting Concrete." Engineering Structures, 30(10), 2945-2956.

Lachemi, M., Hossain, K.M.A., Patel, R., Shehata, M. and Bouzoubaâ, N. (2007). "Influence of Paste/Mortar Rheology on the Flow Characteristics of High-Volume Fly Ash Self-Consolidating Concrete." Magazine of Concrete Research, 59 (7), 517-528.

Liu, M. (2011). "Incorporating Ground Glass in Self-Compacting Concrete." Construction and Building Materials, 25(2), 911-925.

Panesar, D. and Aqel, M. (2014). "Properties of Self-Consolidating Concrete Containing Limestone Filler." International Conference on Construction Materials and Structures (ICCMATS), S.O. Ekolu et al. (Eds.), IOX Press, Johannesburg, South Africa, Nov. 24-26, 772-779.

Rahhal, V., Irassar, E., Castellano, C., Pavlík, Z. and Černý, R. (2014). "Utilization of Ceramic Wastes as Replacement of Portland Cements." International Conference on Construction Materials and Structures (ICCMATS), S.O. Ekolu et al. (Eds.), IOX Press, Johannesburg, South Africa, Nov. 24-26, 208-213.

Sadek, D.M., Amin, Sh.K., Youssef, N.F. (2014). "Blended Cement Utilizing Ceramic Wall Tiles Waste.” International Conference on Construction Materials and Structures (ICCMATS), S.O. Ekolu et al. (Eds.), IOX Press, Johannesburg, South Africa, Nov. 24-26, 152-161.

Siddique, R. and Kunal (2015). "Design and Development of Self-Compacting Concrete Made with Coal Bottom Ash." Journal of Sustainable Cement-Based Materials, Taylor \& Francis, 4(3-4), 225-237.

Uysal, M. and Yilmaz, K. (2011). "Effect of Mineral Admixtures on Properties of Self-Compacting Concrete." Cement and Concrete Composites, 33(7), 771-776. 